\title{
O LOUCO - O PASSANTE - O AGENTE - O CONCEITUADOR
}

\author{
ANNE QUERRIEN*
}

\begin{abstract}
R E S U M O Isaac Joseph foi professor de Sociologia na Universidade de Paris XNanterre. Especialista da escola interacionista simbólica, reintroduziu na França a Escola de Sociologia Urbana de Chicago e se destacou como tradutor de Goffmann, Gumperz, Hannerz. Foi autor de uma obra sobre a microssociologia de Erving Goffmann publicada no Brasil em 1998 pela FGV Editora. É também conhecido por seus trabalhos aplicados de sociologia urbana, publicados na revista Les Annales de la Recherche Urbaine. Desenvolveu importante diálogo com pesquisadores brasileiros da UFF, USP e UFRJ, entre outros temas, sobre escalas do pluralismo e formas de engajamento cívico nos espaços públicos urbanos. Isaac Joseph faleceu em 2 de fevereiro de 2004. Nas palavras de seu colaborador Y. Grafmeyer, Joseph questionou a ilusão que faz crer que a ordem dos fatos só é perceptivel se sairmos de seu detalhe essencialmente irregular, para elevarmo-nos a uma altura suficiente para obter visão panorâmica dos grandes conjuntos. Tinha, porém, a convicção intelectual e militante de que esta atenção minuciosa às civilidades correntes é também portadora de importantes desafios politicos. O presente texto revê o modo como Joseph pensa as interações situadas no espaço da loucura, do passante, da agência e da conceituação.
\end{abstract}

P A L A V R A S - C H A V E Isaac Joseph; interacionismo; microssociologia urbana.

Após o desaparecimento de Isaac Joseph, pus-me a reler, desordenadamente, os diferentes textos que ele nos deixou e que eu havia lido, anteriormente, à medida em que eram publicados. Eles me pareceram todos dotados de uma mesma veia paradoxal, formada, desde logo, a partir do Le passant considerable ou mesmo de Les cahiers de l'immuable. ${ }^{2}$ Ao mesmo tempo em que Joseph nos propõe fazer com Erving Goffman a sociologia da ciência das conversações e de sua comparação, ele nos faz também buscar estas conversações nos personagens encontráveis na sociedade "conversante", à falta de outra expressão, seja do louco, do transeunte que passeia nesta sociedade, do agente de uma conversação imposta por uma instituição, ou mesmo do conceituador que teoriza o que projeta na solidão. A esta lista eu acrescentaria o filósofo-sociólogo que busca, sob o cenário assim montado, o comum, afirmando que não há relaçóes sociais preexistindo às situações, nem recurso possível às origens que são para todos distintas: o encontro se faz entre rostos, membranas situadas entre o domínio de cada um e o domínio comum. Este encontro forma um público, individualizando seus agentes. Estes descobrem-se sustentados por redes, traços materiais de seus percursos, expressão deste "comum" fabricado pelos encontros que se repetem. O comum está por se fazer, não é dado, mas interessa, produz conversa, faz que a sociedade se faça. Como manter juntas estas posições extremas, excêntricas? É isto que o sociólogo nos convida a observar, selecionando para nós as felicidades do passante.
* Tradução de Lucia Reis.

1 I. Joseph, Le passant considérable, Essai sur la dispersion de l'espace public, Sociologie des Formes, $\mathrm{Pa}$ ris, Librairie des Méridiens, 1984.

2 Les cahiers de l'immuable: 1. Voix et voir, abril 1975; 2. Dérives, dez. 1975; Au défaut du langage, nov. 1976; Paris, Éditions Recherches. 
Conheci Isaac Joseph em 1973 quando ele relatou no jornal Libération sua viagem através da rede constituída por Fernand Deligny com suas crianças autistas. Em Les cahiers de l'immuable, realizado junto com Deligny, suas preocupaçôes de fundo estavam já presentes sem as referências sociológicas com as quais ele, em seguida, as desenvolveu. A rede de Deligny na região das Cévennes constituía-se por um certo número de locais de habitação, ligados entre si por trajetos seguidos quotidianamente por adultos e crianças.

Os caminhos dos adultos eram basicamente funcionais: preparação de alimentos, compras, reuniōes, recepção de visitas etc. As crianças executavam movimentos que excediam esta funcionalidade, excediam os adultos: balanços, rodopios em torno de si e outras manifestações não necessárias, que as havia levado, em hospitalizações anteriores, a serem amarradas. Por acaso, dado que um dos adultos havia sido desenhista industrial, Deligny pediu-lhe que desenhasse mapas destes dois tipos de movimentos. Descobriu-se então que aquelas crianças, cujos movimentos tanto inquietavam, permaneciam de fato comportadamente no interior do perímetro definido pelos trajetos quotidianos dos adultos, e desenhavam com estes uma espécie de "corpo comum". Este corpo comum foi visto por Joseph como esperança, um espaço anterior, em cada um de nós, ao uso da palavra. Crianças autistas e adultos normais situavam-se de fato em relação aos mesmos traçados de sua rede. Os mapas permitiram aos adultos mostrar aos pais o que as crianças faziam. O pragmatismo dominou a descoberta para fazê-los desempenhar vários papéis diferentes. A superposição dos mapas permitia identificar pontos de atração, modificações da rede. Os mapas exibiam mobilidade dos membros da rede, seus deslocamentos, suas marcas, e formavam uma imagem mental do território co-produzido pelas crianças e pelos adultos. Para Isaac Joseph, a experiência da rede remete a palavra a seu lugar, libera-a dos efeitos de controle que podem paralisar ou ferir, como já vimos bastante nas assembléias gerais de Maio de 1968 e nas subseqüentes. A presença junto às crianças autistas indica que a palavra não é a finalidade da atividade humana; que esta, para se desenvolver, não necessita dar o mesmo significante à mesma coisa.

Mas Deligny prossegue a pesquisa a partir dos mapas: as "linhas de errância", os percursos bizarros das crianças continuam escapando à compreensão dos adultos, parecendo imantadas por coisas desconhecidas, cuja atração traduz-se por entrelaçamentos, densificações, alguma coisa comum nos trajetos de uma criança, mas singular a estes mesmos trajetos. A criança aparece como indivíduo, humano, na teia de aranha que forma o conjunto da rede. E estes traços singulares tornam-se para Joseph, como uma linguagem: "a rede é uma linguagem posto que consiste na consciência que cada um de nós tem da presença dos outros", e a maneira pela qual ela é expressa em seus trajetos, em seus percursos do território comum.

A criança se reconhece no habitual, distingue os lugares; para ela há um outro identificável, um humano a despeito da ausência da pessoa, a impossibilidade da conversação. Mas Deligny nos lembra: não se deve parar aí; é preciso sempre buscar nos mapas o desconcertante, fazer do comum um motor da exploração.

Transformando sempre suas linhas de errância, ainda que de modo pouco perceptível, as crianças mostram que elas solicitam à rede que ela assegure algo além da comunicação; o que elas fazem quando o fazem aparentemente para nada? $\mathrm{O}$ adulto da rede ou o passante amigo devem ter uma atitude de vigília, ele não possui meios para fazer qualquer interpretação. A psicanálise em nada ajuda em tal situação. Joseph define a tentativa de 
Deligny como "uma jangada sobre a qual idéias e métodos servem para entreter o náufrago em seu projeto. No momento em que elas pesem muito, elas são descartadas para acentuar a deriva”; e acrescenta Deligny, é preciso tomar o máximo de distância possível sob o risco de revelar sua posição.

Desta experiência constituinte, Joseph voltou com a convicção de que a loucura estava no lugar, imbricada na nossa relação complicada com a linguagem e com as linguagens dos outros. Mas o louco das cidades não é mais do que um ator ocasional da reflexão sobre as situações de interação. Por certo, o sociólogo é sensível às anomalias e às situações que embaraçam, mas seu interesse concerne antes ao funcionamento da rede profissional instalada para receber a loucura colhida na rua ou para seguir a formação do diagnóstico nas interaçôes. ${ }^{3} \mathrm{O}$ louco é, por exemplo, aquele que fala sozinho em público e diante de testemunhas, sem prestar atenção à inteligibilidade mútua indispensável à comunicação; um reparo então é necessário à sociabilidade violada, seja porque a pessoa que se excedeu seja capaz de se desculpar, seja porque as pessoas indispostas se afastam e póem fim à interação.

Os loucos são aqueles que perderam a capacidade de distribuir sua atenção segundo ordens rituais que dão acesso aos diferentes recursos da sociedade; são aqueles que se deixam levar, que se deixam tomar ou absorver, aqueles que se desestruturam, aqueles que expõem os pontos onde a ordem das coisas passa a faltar. O louco serve como analisador, mas ele pluralizou-se. A relação com a vida mental socializou-se tornando-se agora visível no curso da vida pública. $\mathrm{O}$ passante não tem mais distância em relação à jangada e à deriva; a loucura expõe-se ao olhar dos profanos, aos pais, aos colegas, aos vizinhos, aos agentes dos serviços públicos. A loucura torna-se presa no universo da mobilidade e circula entre as competências profissionais. Ela tornou-se a loucura do passante.

\section{O PASSANTE}

A figura do passante me parece uma inversão fabulosa do estigma. A condição para a qual o jovem apátrida tinha sido designado é transformada por leituras orientadas em uma síntese das tentativas para fazer dos marginais os melhores observadores sociais: o estrangeiro de Simmel, o migrante de Park, o hobo de Becker, o flâneur de Benjamin. O espaço público é um espaço no qual o intruso é aceito, sem ter necessidade de se identificar; se isso acontecesse de outra maneira, é que o território estaria privatizado. Ser aceito é ter o direito de ir e vir, ser pura presença, aparência de si mesmo, sem interferir, sem interpretar. O flâneur percebe, está aquém da relação convivial face a face, em interação fora da linguagem, não em corpo a corpo mas em aparência, à distância, em civilidade.

A grande cidade com seus transportes coletivos obriga a construir esta capacidade ativa de indiferença que acompanha a troca de olhares, na qual a reciprocidade imediata garante no outro sua alteridade. É preciso situações de alarme para que aquele que passeia saia de sua reserva, e por outro lado hesite fundamentalmente sobre a conduta seguinte, de tal modo, na grande cidade, os marcos que orientam a ação são pouco comuns.

$\mathrm{O}$ passante não quer tocar muito nisso, embora esteja fortemente tocado. Olho enorme e orelha à qual vêm se confessar as paixōes locais. Com sua experiência adquiriu a convicção de que as situações modificam os indivíduos; interessa-se pelas vontades reformadoras, ao mesmo tempo requalificando-as em outros tantos percursos individuais que se reencontrarão talvez na eficácia, por sorte. Enquanto isso, ele descreve, analisa, observa
3 I. Joseph, «La relation de service et les urgences psychiatriques", Les Annales de la Recherche Urbaine, n.73, p.5-13, dez. 1996. 
o percurso de uns e outros, olha aquilo que daí vem a olhá-lo, passando. O passante se sente como o membro do público de um teatro, no qual os papéis secundários fazem muitas vezes a ação quando os primeiros a declamam.

Ele não perdeu no entanto o desejo e a crença na unidade deste mundo, mas com o microssociólogo, com Goffman, ele a encontra na situação mesma, esta espécie de holograma do social, momento de co-produção e co-adaptação fugidias, imagem na qual se espelha o público, que é remetido logo a suas individualidades e hesitaçóes. $\mathrm{Na}$ encenação das relações sociais, a experiência individual é imediatamente coletiva, formada pela transmissão de rituais de interação, mais ou menos adaptada, posto que mais ou menos desterritorializada. O passante não tem necessariamente todo o conhecimento necessário ao acordo perfeito com o ritual, mas este acordo é sua meta e desta distância ele obtém conhecimento da situação, mesmo que não intervenham os rituais de reparação aos quais Goffman consagrou tanta importância: o passante tem um conhecimento humano do social, aquele veiculado por todo ser sem palavra. Como o afirma fortemente Isaac Joseph, a multiplicação dos microlugares e a afirmação do direito a eles, assim como à diferença, suprime o sentido do intervalo entre o homem e seus semelhantes que se situa no fundamento do político como afirmação do humano externo à identidade.

Mas com o pragmatismo, o passante mergulha ainda mais adiante na exploração do mundo, pronto a aplicar seus conhecimentos a seu uso, com precauções. Para lançar-se no mundo é preciso buscar sua própria singularidade e assinalar regularmente sua posição, permanecer passante, não cair na fraternidade, na complacência. É assim que se salva a face do outro, mantém-se a distância em relação a ele e uma possibilidade sempre aberta de negociação. "Porque um espaço público não é nunca uma boa forma [diz Joseph], é preciso nele introduzir formas." Não se trata mais do que um espaço de rumores onde as pessoas colocam-se problemas, conversam entre si, partilham o saber, interaçóes situadas cuja definição modifica sua própria dimensão. O passante não se atribui, para moldar este espaço, qualquer autoridade, ele simplesmente assinala.

E o passante examina as rotinas que estabelecem neste espaço público um certo sentido do comum, que definem as aparências normais com base nas quais os comportamentos serão julgados aceitáveis, que estabelecem um contexto que torna possível a conversação. Mas o passante identifica já algum mal-estar nestas interações, a multiplicação dos estigmatizados com os quais os normais nunca mantêm conversações correntes. É daí que surgiu a necessidade de redefinir as civilidades, não pela reparação da interação individual, mas sim englobando mais possibilidades nas situaçōes, tornando-as sempre mais abertas à diversidade da qualificação social, pondo em reserva as categorias estigmatizantes, obrigando-se à indiferença, vestindo o humano com polidez. Trata-se para o passante, ao mesmo tempo, de um aprendizado do rosto do outro e de uma doação de forma, a proposição de uma reciprocidade, o devir passante do outro. Dissimular é, em primeiro lugar, permitir ao outro dissimular.

O passante confronta-se aos limites situados entre ele e o outro, entre o que se faz e o que não se faz, ao imperativo de deixar o outro entregue a suas ocupações, quaisquer que sejam os sentimentos de atração ou repulsão que ele experimente. O summum da sociabilidade na grande cidade encontra-se na suspensão da interação, no respeito, em um entreato situado entre os códigos e os territórios que definem as comunidades de bairro. Há neste entreato proposto pelo passante uma carga de angústia não desprezível quanto ao devir da humanidade. No entanto, este entreato constitui um esplêndido espetáculo quotidiano. 
Isaac Joseph insiste: mesmo se identificarmos o outro pelas aparências, por sua roupa, seu estilo, nada saberemos daquilo que o anima, das razóes que o levam a seguir seus códigos; temos disto um belo exemplo com a questão do véu. 'O passante confrontado a um excesso de sentido não pode mais que aumentar sua reserva se ele não quiser cair na a-sociabilidade da usurpação territorial. E ampliar sua reserva consistirá em seguir seu caminho, sair desta interação presente para entrar em outra no mesmo ou noutro local. O passante vive por sequências que ele capta no mundo constituindo sua própria trajetória, que não é igual à de nenhum outro, o que Joseph chama de "engajamento problemático".

Mas este passante que atravessa o mundo enviando-lhe imagens de seus pontos sensíveis tem de algum modo consciência de que os modos de ser em público não podem ser analisados somente pela lógica da dispersão. O espaço público constitui-se pela lógicas de redes segundo as quais coordenam-se as situaçóes, pelas quais os passantes encontram acesso aos recursos, às carreiras e a um conjunto de personagens e objetos intermediários na constituição dos territórios. A face estável do mundo mostra seu rosto, como o "costumeiro" indicava o comum à criança louca. Quem é o agente deste costumeiro urbano?

\section{O AGENTE}

Não há passante sem agente, sem princípio ativo, sem espaço institucional mantido em diversos pontos, vetorizado pela disciplina. Joseph encontra o agente em Disciplines à domicile. ${ }^{4}$ Diferentemente do professor que utiliza abundantemente a linguagem e os signos, o agente observa, explora, relata, torna a relação impessoal e o olhar onipresente. A passagem de Joseph ao Plano Urbano ${ }^{5}$ e sua proximidade com a RATP (empresa pública responsável pelo metrô de Paris ${ }^{6}$ dão ao agente uma variação contínua. A relação de serviço entre agentes e usuários repete a cooperação dramatúrgica desenvolvida pelo passante no espaço público, e permite-lhe exercer seus talentos. O passante sublinha as dificuldades desta relação, as competências organizadas pelo agente, sua inventividade em relação aos procedimentos, sua capacidade de se adaptar aos diferentes públicos mantendo a fachada de sua organização, sem fingir humildade da organização comercial em face do cliente. $\mathrm{O}$ passante defende com fervor o serviço público, pequeno consertador infatigável das falhas sociais. Mas a modernização faz crescer o micropoder do agente e seus riscos de discriminação ligados à segmentação crescente do público-alvo, ao mesmo tempo que aumenta suas incertezas quanto ao devir da organização.

Ora, o público superestima sua relação com o agente; usuários e agentes são nostálgicos da sociedade de interconhecimento e de controle social sem a qual sua interação não teria razão de ser. Os agentes têm o sentimento de ter perdido as normas partilhadas com os freqüentadores. Quanto mais os serviços são abertos e acessíveis, constata Joseph, mais fazem falta as normas partilhadas. $\mathrm{O}$ agente nem sempre está preparado para a demanda de explicitação ou de legibilidade que daí decorre. Ele tem medo de se desmoralizar. Então ele tem que enfrentar, com pedagogia e doçura, retransmitir as regras do serviço. As competências do agente - juízo, observação, diagnóstico, negociação, distanciamento não são competências individuais, mas rotinas vinculadas à atividade, à organização. Elas definem uma maneira de ser no trabalho.

O agente diante do público é a fachada da organização, um tradutor de sua complexidade, de suas exigências, de suas falhas e de sua reparação, em uma linguagem acessível.
* A autora refere-se aqui à polêmica instaurada na França em torno à medida governamental que proibiu às estudantes mussulmanas o uso do véu em escolas públicas. (N. E.)

4 P. Fritsch, I. Joseph e A. Battegay, Disciplines à domicile, Paris, Éditions Recherches, 1977.

5 G. Jeannote e I. Joseph, Métiers du public: les compétences de l'agent et l'espace de l'usager, Éditions du CNRS, 1995.

6 I. Joseph, Météor, Les métamorphoses du métro, Economica, 2004. 
Ele é tomado por uma multiplicidade de demandas e não se deve por demais consagrar a uma em detrimento das outras. Ele só se deve engajar naquilo que a organização é capaz de enfrentar e portanto saber a que se ater. É necessário que mobilize sua experiência anterior para se preparar ao que se seguirá. $O$ passante que o observa procura identificar as condições desta coordenação, em geral feliz, de papéis profissionais contraditórios. Ele recenseia situações-tipo para identificar os constrangimentos organizacionais e rituais que são exercidos sobre o trabalho do agente. Dispensar ao usuário a mesma atenção de nada serve, pois ele não é o mesmo todo o tempo; ele é aquilo em função do que varia o trabalho do agente. $\mathrm{O}$ usuário raramente apresenta-se em coletivo, e praticamente sempre fora das situações de trabalho. Entretanto, é o conjunto dos usuários que serve de referência ao agente para animar sua conversa com cada um e levar a pequena cena rumo à conclusão de um acordo. O agente não faz mais do que ajustar uma oferta a uma demanda; ele articula vários registros de conhecimentos e de constrangimentos e com freqüência experimenta a fragilidade de seus quadros de interpretação das situações. Ele trabalha, às vezes perdidamente, para reunir estes quadros, para obter aquiescência. Raros são os usuários que trabalham igualmente nesta direção. Caso eles cooperassem demais, eles colocariam mal o agente. $\mathrm{O}$ espaço de deslocamento põe-se à disposição dos usuários; ele só é espaço de trabalho para os agentes. E o passante, com suas observações, é aí visto com freqüência como um estorvo tal como na rede de Deligny.

No entanto, o passante insiste, insiste tanto mais quanto a empresa interroga-se sobre sua capacidade de se modernizar. A busca de modernização faz-se antes no domínio da inovação técnica: direção automática e arquitetura impositiva são no Météor os vetores de uma renovação na qual os agentes em contato com o público não parecem de modo algum estar no centro da reflexão. Por certo, um acordo foi feito entre a empresa e os sindicatos que na linha de metrô 14 reúne pessoal de manutenção e de operação num só corpo e confia aos antigos condutores a tarefa de devolver o material defeituoso à garagem. Certos agentes apaixonaram-se por esta inovação e tornaram-se passantes à sua maneira, consagrando tempo a observar nesta nova linha todos os problemas de operação que ocorrem quotidianamente em outros locais. $\mathrm{O}$ acordo prevê a limitação no tempo desta nova condição dos agentes. Novas identidades profissionais devem ser definidas, novos agenciamentos coletivos devem ser apreendidos e experimentados. Lendo-se Joseph, parece que é na relação com o usuário que se deve buscar esta operação. Os agentes dispõem agora, com a nova linha automática, de um plano de trabalho comum tão consistente que o usuário apenas acrescenta uma singularidade, faz que algo aconteça. Cada usuário torna-se um ser singular e considerável e não uma anomalia a ser polidamente ajustada à regra; cada usuário com problema designa um ponto a ser melhorado na rede, para atender ao plano de trabalho comum. O novo metrô quer integrar o usuário em seu plano de cognição distribuída, fazer girar as posiçóes de agente, passante, usuário em torno da mesa, coletar as informações em benefício de todos, organizar a copercepção das situações. Descolado de seu papel tradicional, o agente flutua no espaço institucional ou reduz-se, ao contrário, a suas tarefas de base. Mas o passante não coopera apenas com os agentes. O espaço não é sustentado somente pela linguagem dos agentes, reproduzido pelas interaçôes entre agentes e usuários; ele é instituído materialmente por conceituadores. 


\section{O CONCEITUADOR}

Entre estes conceituadores, encontramos o próprio filósofo-sociólogo, produtor de conceitos, ou o que retoma conceitos colhidos e traduzidos de trabalhos norte-americanos. Estes conceitos não representam um conjunto de objetos ou de situações que vamos designar pela mesma palavra de acordo com nossa formação clássica. Impossível utilizar o conceito de espaço público ${ }^{7}$ em Isaac Joseph num curso de licenciatura com a pretensão de trazer exemplos semelhantes de interrogação de estudantes; o espaço público parece explodir, segundo as comunidades, as experiências, os meios. O conceito é então um guia para a ação em situação, ou melhor, uma proposta para nela se localizar, para não fugir pelos corredores do metrô ou dos conjuntos habitacionais do subúrbio ao primeiro incidente, para se instalar nas lentes do passante. Mas do leitor, mesmo esclarecido, ao passante eficaz, há uma grande distância.

Iluminar as estações e as plataformas das estradas de ferro vai talvez permitir ao público ocupar seu lugar. ${ }^{8}$ A luz é o primeiro princípio ativo do espaço público. Joseph associa seu amigo Larent Fachard, conceituador da iluminação nos trabalhos de renovação da estação ferroviária Gare du Nord, à reconquista dos espaços públicos do metrô. Ele faz o paisagista Bernard Lassus analisar a alternância de sombra e luz que torna o metrô aéreo agradável. Ele interroga infatigavelmente arquitetos e críticos sobre as coordenadas de um espaço de visibilidade no qual a reciprocidade de perspectivas se tornaria possível, onde os viajantes não seriam apenas conduzidos mas acolhidos, um espaço acessível às pessoas sem domicílio fixo e aos artistas de rua, onde a civilidade seria facilitada, onde o reencontro se tornaria feliz. "Expor o transporte coletivo na cidade", diz ele falando dos projetos de Bernard Kohn que teriam feito das estações de Météor poços de luz quase revolucionários, "conceber um espaço monumental pela escolha de formas e de materiais, era mergulhar no patrimônio do metrô, restaurar sua poesia histórica para restituí-la no presente, ganhar a consideração do passante de hoje, associar modernização e serviço público" ${ }^{9}$ O fuck context de Rem Koolhas, mesmo se ele é cheap, se não é caro, não é a preocupação de Joseph, quando ele pensa em concepção.

É na arquitetura das aerogares, a partir de Paul Andreu, que ele encontra um eco a suas exigências, uma arquitetura que ele diz animada pela preocupação dos serviços de pós-venda, mas que tenta sobretudo criar passagens entre diferentes tipos de luz, ao longo de todo o caminho nos espaços sucessivos da viagem, como podemos ler no texto do próprio arquiteto. Paul Andreu não está apenas a serviço dos edifícios que ele cuida, como o demonstra Joseph numa visão de sociólogo; ele tem sua própria visão, enraizada nos céus da cidade próxima do mar, Bordeaux, onde ele nasceu, céus em nome dos quais ele negocia com os fornecedores os azuis, os rosas, os cinzas, os jardins, graças aos quais o serviço será realizado com prazer. ${ }^{10}$ Para Paul Andreu, o espaço sensível é individualizante pela sua beleza, pela sua qualidade, o que também afirma Joseph referindo-se ao conceito de luz. É a beleza da arquitetura, mais ainda que o bilhete de transporte, que estimula o indivíduo a se diferenciar da multidão, formando um público civil, exigente em relação a ele próprio e em relação aos outros. $\mathrm{O}$ arquiteto não negligencia a função, as linhas de controle que devem ser passadas, as zonas de espera que devem ser respeitadas. Mas, o que é muito importante, não é a função, o serviço de terceiros, que dita a forma; é o meio ambiente paisagístico e cultural no qual se insere o edifício. Este é concebido como "um espaço de espera”, um lugar de imobilidade imperceptível no qual o movimento se interrompe e retoma, no qual o viajante deveria poder se confrontar com sua angústia,
7 I. Joseph (dir.), L'espace du public, Les compétences du citadin, Colloque d'Arc et Senans, 8-9-10 de novembro de 1990, Éditions Recherches - Plan Urbain, 1991.

8 I. Joseph (dir.), Prendre place, Espace public et culture démocratique, Colloque de Cerisy, Paris, Éditions Recherches - Plan Urbain, 1995.

9 I. Joseph, Météor, Les métamorphoses du métro, Paris, Economica, 2004, p.51.

10 P. Andreu, J'ai fait beaucoup d'aérogares, Les dessins et les mots, Paris, Descartes et Compagnie, 1998. 
$11 \mathrm{H}$. Gaudin, "Seuil et Totem", in I. Joseph (dir.), Prendre Place, Paris, Éditions Recherches - Plan Urbain, 1995. confrontação indispensável à sua transformação em indivíduo membro de um público, confrontação que proíbe a banalização mercantil crescente do espaço de transporte. À diferença de outros arquitetos que fazem fotografar seus prédios vazios de usuários, vistos como os que poluem, para Paul Andreu, é o movimento e as cores dos passageiros que dão vida à obra, que dão forma ao prédio de seus sonhos, um prédio no qual os acasos são acolhidos e combinados de maneira indissociável, sem hierarquia, sem composição de conjunto que rejeitaria suas aleatoriedades como outras tantas tarefas. Como o pólo de integração entre transportes terrestres, a aerogare é um lugar de interconexão onde as velocidades diferentes anulam-se em pontos singulares. Os lugares de espera e de encontro, as estaçôes, lá onde o tempo não tem evento, ou é pontuado de microeventos.

Henri Gaudin, o outro arquiteto de que Joseph gostava, interessa-se igualmente pelos pontos de intensidade no cruzamento das passagens e trajetórias, pelo que se faz pertencer a um espaço comum ainda que permanecendo indivíduos, seres livres e não destinados aos mesmos percursos. ${ }^{11} \mathrm{~A}$ arquitetura refere-se à harmonia das multiplicidades, não como uma orquestração imposta que subsistirá na ruína, mas como uma possibilidade oferecida aos vivos. "Os prédios produzem um espaço comum inteligível que nos intervalos pertence a cada um", diz Henri Gaudin. Trata-se de "reduzir a exterioridade incompreensível da materialidade, arranjando os limites, traçando caminhos”, dispondo as coisas, afastando-as, reagrupando-as. Para Henri Gaudin a arquitetura deve fazer que a fachada pertença ao outro e não ao um, preserve a face do outro, no dizer de Joseph, o respeite, na linguagem quotidiana. "Neste limite onde o muro termina, saudamos aquele que chega", praticamos a hospitalidade. Henri Gaudin fabrica clareiras, como a desenhada na capa do livro coletivo Prendre Place, como aquelas onde se acomodam os esportistas no estádio Charléty em Paris, ou os objetos vindos da Ásia para o Museu Guimet de Paris.

Com estes arquitetos, como com o trabalho de Isaac Joseph, bem como com muitos trabalhos artísticos contemporâneos, saímos de uma cenografia da representação, para fazer a construção do público, a construção de um evento infinitamente repetido à medida que o público acrescenta seus ingredientes. Para o conceituador trata-se de enquadrar as perspectivas e o lugar da ação com suas dimensões conhecidas, mas também uma grande parte de desconhecido, como sublinha Paul Andreu a propósito das extensões rápidas dos aeroportos. É preciso recortar o espaço, organizar as séries de seqüências, os percursos possíveis. O espaço arquitetural trata então da aproximação, dos limites, das saídas, do confronto com os grandes dados sensíveis como a sombra, a luz, o som, a cor. Para Isaac Joseph, o espaço deve ser considerado ativo, ser concebido, expor qualidades sensíveis. Nos transportes coletivos assim como na rua, trata-se de gerenciar redes de pessoas imersas em culturas diferentes graças a uma cultura profissional e técnica cujo quadro arquitetural deve facilitar a legibilidade, a capacidade de localização. É essa cultura que deve ser exposta, como os objetos asiáticos no museu, para permitir aos viajantes tornaremse públicos, indivíduos separados por intervalos, diferentes num espaço comum. Cuidar da rua requer considerar as rupturas sociais e culturais como habitáveis, organizáveis, e não buscar um acordo, além do mais impossível, nas semelhanças morfológicas. Esta habitabilidade, o único senso comum possível, só pode provir de um esforço de pensamento, de construçãa. 


\section{A POLÍTICA DE ISAAC JOSEPH}

A microssociologia de Joseph é profundamente política no seu princípio básico, a reciprocidade de perspectivas como forma de troca, a possibilidade de olhar as coisas do ponto de vista do outro. "Qual é a consistência do como se que nos faz iguais em humanidade?”, diz ele. Não é preciso um modelo, um símbolo de uma nova cidadania ou de uma nova humanidade, como propuseram inúmeros regimes caídos sob o peso de suas torturas e idiotices. A dimensão do desejo de lugar comum existe na tensão entre proximidade espacial e distanciamento social; a dimensão da repulsão tão evidenciada pelos sociólogos significa desejo de uma outra agregação com este lugar comum. A atividade política é uma réplica no correr das coisas, um ataque que se distancia da simples co-presença, designa um sentido de humanidade que não pode ser o do retraimento. A cidade deve ser acessível, o que implica que ela não seja organizada em comunidade, que ela não seja descrita como formada por comunidades por aqueles que a explicam, e que então esses últimos escolham outras coordenadas, tomem a distância que caracteriza o passante: estar presente sem aderir, manter sua mobilidade.

Joseph insiste em todas as descrições do trabalho do agente na dimensão de tranqüilidade que este dá a sua intervenção. É neste ponto que, apesar de suas denegações, ele pratica bem um interacionismo que se pode qualificar como simbólico, sustentado pelo modelo de igualdade democrática como símbolo da co-presença feliz. Para ele a democracia é um modo de vida mais que uma forma de governo - porque ela comporta inúmeros excluídos que no entanto participam do modo de vida. Formamos juntos uma comunidade aberta de exploradores, caracterizada pela presunção de igualdade de julgamento entre todos os seus membros, apesar da pluralidade de linguagens. E somos todos filiados ao durável pelo motor da exploração que é a necessidade de chegar a um acordo nos encontros. Desta multiplicidade de acontecimentos produzimos um plano de consistência sobre o qual se segue a criação contínua de nosso modo de vida democrático.

A grande cidade é o teatro privilegiado desta criação porque ela organiza, mais que qualquer outro lugar, o que Joseph chama de "a vulnerabilidade estrutural do laço social", a exigência permanente para todos e qualquer um de trabalhar nela, de reconfigurá-la.

Concluirei com uma frase de Joseph: "O acordo buscado pelo pesquisador com o que ele observa é ao mesmo tempo político e prático: não ocorre um ideal de familiaridade, e não se trata de um estado de imersão ou de integração, mas de um desejo e uma crença, um movimento dois em um do pensamento integrado, do pensamento cioso de sua impotência, incapaz de se constituir em generalidade mobilizando os vocabulários disponíveis". ${ }^{2}$

\section{REFERÊNCIAS BIBLIOGRÁFICAS}

ANDREU, P. J'ai fait beaucoup d'aérogares, Les dessins et les mots. Paris: Descartes et Compagnie, 1998.

FRITSCH, P.; JOSEPH, I.; BATTEGAY, A. Disciplines à domicile. Paris: Éditions Recherches, 1977.

GAUDIN, H. Seuil et Totem. In: JOSEPH, I. (Dir.) Prendre Place. Paris: Éditions Recherches - Plan Urbain, 1995.

JEANNOT, G., JOSEPH, I. Métiers du public: les compétences de l'agent et l'espace de l'usager. Editions, 1995.
12 I. Joseph, La ville sans qualités, La Tour d'Aygues, Éditions de l'Aube, 1998.

Anne Querrien é editora dos Annales de la Recherche Urbaine. E-mail: anne. querrien@equipement. gouv.fr

Artigo recebido em abril de 2004 e aceito para publicação em maio de 2004. 
JOSEPH, I. Le passant considérable. Essai sur la dispersion de l'espace public. Sociologie des Formes. Paris: Librairie des Méridiens, 1984.

. (Dir) L'espace du public, Les compétences du citadin. Colloque d'Arc et Senans, 8-9-10 Novembre 1990. Éditions Recherches - Plan Urbain, 1991.

. (Dir.) Prendre place. Espace public et culture démocratique. Colloque de Cerisy. Paris: Éditions Recherches - Plan Urbain, 1995.

JOSEPH, I. La relation de service et les urgences psychiatriques. Les Annales de la Recherche Urbaine, n.73, p.5-13, 1996.

. La ville sans qualités. La Tour d'Aygues: Éditions de l'Aube, 1998.

. Météor, Les métamorphoes du métro. Paris: Economica, 2004.

. Les cahiers de l'immuable: 1 . Voix et voir. Paris: Éditions Recherches, n.18, abril 1975.

. Les cahiers de l'immuable: 2. Dérives. Paris: Éditions Recherches, n.20, dez. 1975.

. Les cahiers de l’immuable: Au défaut du langage. Paris: Éditions Recherches, nov. 1976.

A B S T R A C T Isaac Joseph was professor of Sociology at the University of Paris X - Nanterre. Specialist on the school of symbolic interactionism, he also reintroduced in France the Chicago School of Urban Sociology and is well known as translator of Goffmann, Gumperz and Hannerz. He wrote a book about the microsociology of Erving Goffmann, published in Brazil in 1998 by FGV Press. He is also known for his works on urban applied sociology, published in Les Annales de la Recherche Urbaine. He developed an important dialogue with Brazilian researchers from UFF, USP e UFRJ, on issues like the scales of pluralism and the forms of civic engagement in urban public spaces. Isaac Joseph died on February 2004. In the words of his friend Y. Grafmeyer, Joseph questioned the illusion that makes think that the order of facts is only perceptible if we leave its essentially irregular details to reach sufficient height to get a panoramic view of the big wholes. He had, although the militant and intellectual conviction that this detailed attention spent to ordinary civilities is also rich in important political challenges. This article discusses the way Isaac Joseph treats the interactions situated in the spaces of madness, passing, agency and conceptualizing.

K E Y W O R D S Isaac Joseph; interactionism; urban microsociology. 